\title{
Sintomas de stress na rede pública de ensino
}

\author{
Maria do Sacramento L. Tanganelli ${ }^{1}$ e Marilda E. Novaes Lipp ${ }^{2}$ \\ Pontifícia Universidade Católica de Campinas
}

\begin{abstract}
O Inventário de Sintomas de Stress Infantil (I.S.S.I. ) foi administrado a 158 alunos de $1^{\mathrm{a}}$ a $4^{\mathrm{a}}$ série das escolas de periferia da rede pública de ensino da cidade de Americana, com o objetivo de averiguar o nível de stress dos escolares. A população foi dividida em 2 grupos de alunos, fortes e fracos, de acordo com os critérios das professoras. A amostra de alunos fracos apresentou maior sintomatologia de stress com predominância de sintomas cognitivos.
\end{abstract}

Palavras-chave: Desempenho, Ensino, Escolares, Stress.

\begin{abstract}
Stress symptoms in the public school system

The Stress Symptom Inventory for Children (ISSI) was applied to 158 children, grades one trough four in a public school attending a low income neighborhood in the city of Americana, in São Paulo, Brazil. The objective was to survey the stress level in the public school students. The sample was divided into two groups composed by either high or low achievers, according to the teacher's evaluations. The academically weak students showed greater number of stress symptoms than te others. Most symptoms were of a psychological nature.
\end{abstract}

Key words: achievement, teaching,, school children, stress

O termo stress tem se tornado nas últimas décadas um dos temas mais populares tanto no que se refere à pesquisa na área da saúde mental quanto na prática.

No Brasil, recentemente Lipp et al (1996) organizou a obra intitulada "Pesquisa sobre Stress no Brasil" em que as autoras apresentam uma coletânea de estudos realizados com diversas populações abrangendo as áreas da saúde, ocupação e grupos de risco. Interessante ressaltar que em todos os grupos estudados foi constatada alta incidência de sintomas de stress. Tal fato justifica a importância que têm para a saúde da população esses estudos.

1. Doutoranda e bolsista CAPES-DS.

2. Docente do Departamento de Pós-Graduação em Psicologia da PUC-Campinas.

Endereço para correspondência: Departamento de pósGraduação em Psicologia, Rua Waldemar César da Silveira, 105, CEP 13045-270, Campinas,SP
Atualmente os pesquisadores da área da saúde têm procurado dar maior importância às atitudes preventivas, com o intuito de estabelecer planos de atuação precoce. Dessa forma os estudos na área de stress infantil, tornam-se de grande importância.

Stress é uma reação do organismo em função de alterações psicofisiológicas que ocorrem na vida do indivíduo quando este se depara com situações que o amedrontam, excitam, confundem ou até mesmo o fazem extremamente feliz.

Lipp et al (1991) coloca que o stress infantil é como o do adulto, caracterizado por um desgaste geral do organismo. A criança quando se vê frente a um estressor, reage com sensações físicas e psicológicas, sendo que as conseqüências do stress excessivo ou prolongado podem levar a problemas graves de saúde. As conseqüências para a criança podem estar associadas na patogênese de distúrbios físicos e psi- 
cológicos. Os distúrbios psicológicos mais comuns são: depressão, enurese, dificuldades de relacionamento, comportamentos agressivos, desobediência inusitada, ansiedade, choro excessivo, gagueira, dificuldades escolares, pesadelos, birras, insônia. Os distúrbios físicos relacionados ao stress são a obesidade, a asma, doenças dermatológicas, cáries, entre outros.

Segundo Carson e Schauer (1994) a atitude de terapeutas, professores, pais e outros profissionais que trabalham com crianças é um fator que contribui para desencadear ou atenuar o stress em crianças.

Sobre a influência dos pais no desencadeamento ou agravamento de stress em crianças, Lipp (1989) enfatiza que estes influenciam na medida em que contribuem para que os filhos desenvolvam características pessoais de propensão ou não ao stress na vida adulta. Segundo a mesma, autora as atitudes dos pais exercem papel relevante na vulnerabilidade e na resistência que a pessoa virá a ter ao stress e essa relevância se dá em termos de influência tanto da hereditariedade quanto em termos ligados a aprendizagem.

A autora coloca a importância de fontes de stress que advém dos pais e que acabam por contribuir para uma maior ou menor vulnerabilidade ao stress, tais como a aquisição de confiança em sua própria atuação no mundo, através da história de reforço e punição, modelagem e modelação, fornecidas basicamente pelos pais. Ressalta a aprendizagem de crenças e valores que podem funcionar como fontes internas de stress; locus de controle, ansiedade, estilo passivo/ativo e comportamento Tipo A ou B.

Alcino (1995) constatou, em seu trabalho realizado com crianças, que os filhos de pais hipertensos apresentavam maior sintomatologia de stress.

Para a autora há ainda outras fontes internas de stress ligadas às atitudes parentais, tais como a vulnerabilidade ao stress associada à frustração.
Cummings (1994, apud Wagner e Biaggio, 1997), em estudo realizado sobre a repercussão dos conflitos dos pais no desenvolvimento das crianças, constatou que a raiva dos adultos, por exemplo, é estressante e desgastante para as crianças quando estas presenciam conflitos entre os pais.

São inúmeros os trabalhos existentes na literatura sobre stress em estudantes universitários e stress dos professores, porém há uma grande carência de estudos voltados para o nível básico de ensino, o que também foi observado por Vilella (1995) e Tricolli (1997).

Segundo Lipp et al (1991), a escola pode ser um fator estressante na vida da criança em função do seu ambiente físico, por se o primeiro local em que a criança desenvolve seu aspecto social, pelo material pedagógico inapropriado e atividades inadequadas. Também, o comportamento inadequado dos professores com cobranças exaustivas e aceitação ou rejeição por parte dos colegas são importantes eventos na vida das crianças.

Capel (1987, apud Lamude, 1992), menciona que os fatores relacionados ao stress mais amplamente pesquisados, que contribuem para os comportamentos negativos dos professores em sala de aula são: "bournout", comportamento Tipo A, conflito de papel e ambigüidade de papel.

Professores "bournout" dão menos informação, fazem menos elogios e mostram menos aceitação das idéias de seus alunos. Professores do Tipo A promovem hostilidade na classe em função da motivação para a realização, agressão e impaciência. A ambigüidade de papel foi significativamente associada com a maior tensão dos alunos, metas e padrões de desempenho obscuros, enquanto que o conflito de papel tem sido associado com menor satisfação, envolvimento e comprometimento dos alunos.

Sobre o stress do professor no Brasil, Reinhold (1985) concluiu que a suscetibilidade 
ao stress encontrada no professor deve-se a uma série de mudanças que este vem sofrendo em sua vida profissional, o que o leva a uma reação de stress ou "bournout" principalmente em professores de alunos de pré-primário e de $1^{\mathrm{a}}$ a $4^{a}$ série.

Ainda estudos como os de Lima (1986, apud Tricolli, 1997) enfatizam que a escola pública não dá oportunidades iguais para as crianças das diferentes classes sociais. Segundo os autores, os professores chegam a rejeitar certos alunos de forma explícita.

No que se refere aos estudos com alunos do ensino básico no Brasil, podemos citar os estudos de Vilella (1995) e Tricolli (1997) em alunos de $1^{\mathrm{a}}$ a $4^{\mathrm{a}}$ série de escolas públicas e particulares em que foi verificada alta incidência de sintomas e fontes de stress.

O stress infantil pode decorrer de causas externas ou internas, sendo que a família e a escola podem ser geradoras de inúmeras fontes de stress. Em seu trabalho, Vilella (1995) apontou que o elevado nível de stress era proveniente mais de fontes internas de stress do que externas, citando problemas com relação a auto-estima, ansiedade antes das provas, insegurança e medo de Deus, entre outras. Tricolli (1997) também observou forte presença das fontes internas de stress sendo que as mais mencionadas estão de acordo com os trabalho de Vilella (1995).

Para Lipp (1991), o número de crianças com sintomas de stress vem aumentando. Entre outras coisas que podem colaborar para esse fato, está a independência e maturidade precoce, além da permissividade sexual.

Quando a criança está sob fontes de stress, assim como o adulto, ela também pode apresentar sintomatologia de stress tanto a nível físico como psicológico.
Os sintomas de stress a nível físico são: dor de cabeça, náuseas, tique nervoso, hiperatividade, ranger dos dentes, gagueira e enurese noturna.

Os sintomas psicológicos mais observados são: agressividade ou impaciência, pesadelos, depressão, medos, dificuldades de relacionamento.

Vilella (1995), Alcino (1995), Bignotto (1997), Tricolli (1997) realizaram trabalhos com populações infantis, sendo que os resultados apontaram para alta sintomatologia de stress com uma incidência de sintomas de stress cognitivo.

Pelo exposto acima, presume-se que a família e a escola exerçam forte influência no desenvolvimento da resistência ou vulnerabilidade ao stress. Dessa forma, conhecer as causas do stress na infância e desenvolver programas de controle do stress específicos para essa população torna-se crucial, pois, dessa maneira, pode-se preparar a criança e aqueles que diretamente participam do seu desenvolvimento para lidar de maneira mais eficaz com sua sintomatologia de stress e também trabalhar a nível de prevenção. Dessa maneira, estudos e pesquisas fazem-se necessários.

O presente estudo focalizou crianças de $1^{\mathrm{a}} \mathrm{a} 4^{\mathrm{a}}$ série, por ser a escola um meio onde além da criança passar grande parte de sua vida, convive com grande número de exigências e expectativas e enfrenta dificuldades que advém da relação aluno/professor.

Os objetivos foram verificar a incidência de sintomas de stress em crianças da $1^{\mathrm{a}} \mathrm{a} 4^{\mathrm{a}}$ série de escolas de periferia da rede pública de ensino e os tipos de sintomas prevalentes, bem como comprovar o stress de alunos fortes e de alunos fracos. 


\section{Método}

\section{Sujeitos}

Participaram desta pesquisa 158 crianças de ambos os sexos, na faixa etária de 7 a 13 anos, alunos de escolas da rede pública de ensino da cidade de Americana, localizadas em bairros da periferia. Na sua grande maioria a amostra era composta por crianças de classe socioeconômica baixa, com média de idade de 9 anos e 2 meses.

\section{Material}

Para a realização da coleta dos dados, foram utilizados: uma Ficha de Identificação dos Sujeitos e o Inventário de Sintomas de Stress Infantil I.S.S.I. (Lipp e Romano, 1987).

Ficha de Identificação dos Sujeitos: Este instrumento foi elaborado com o objetivo de coletar dados pessoais, informando sexo, idade e série escolar e era preenchido pelo professor da classe, que à parte colocava uma observação:

- S-aluno forte ( considerado pela professora como aluno sem problemas quanto ao aprendizado ).

- F - aluno fraco ( com problemas no seu aprendizado ).

A classificação dos alunos ficou a cargo da professora de classe, que se baseou nos seus próprios conceitos para a classificação.

Inventário de Sintomas de Stress Infantil I.S.S.I. (Lipp e Romano, 1987): O instrumento tem por finalidade verificar a presença e a intensidade de sintomas de stress e ainda identificar se os sintomas relatados são de natureza somática ou cognitiva. É composto por quatorze itens, sete se referindo a sintomas somáticos e sete a cognitivos. Cada frase que descreve o sintoma apresenta um círculo que é dividido em quatro partes, sendo estas preenchidas pelas crianças de acordo com a intensidade com que esta o percebe em si mesma. Considera-se como uma criança com sintomatologia significativa de stress aquela que apresenta um total a partir de 21 pontos na soma das áreas de sintomas Somáticos e Cognitivos ou verificando-se em qualquer das áreas um total de quatro círculos pintados em três ou mais itens.

\section{Local}

A pesquisa foi realizada nas próprias escolas, em salas de aulas adequadas e em horário de aula para que o barulho do recreio não atrapalhasse a aplicação dos instrumentos.

\section{Procedimento}

Inicialmente foram selecionadas nove escolas. Os critérios para a escolha referiam-se à localização das escolas, que deveriam estar em bairros da periferia da cidade e ao número de alunos.

Foi feito um primeiro contato com as diretoras das escolas, no qual era exposta a importância da pesquisa.

Das nove escolas, três diretoras dispensaram a pesquisa alegando problemas como: reformas no prédio, falta de tempo no momento e dificuldades em estar recebendo a pesquisadora. O número de escolas ficou sendo então seis.

Em uma segunda etapa manteve-se contato com as coordenadoras de primeira a quarta série, com o objetivo de passar uma breve explicação sobre a pesquisa, o procedimento que elas seguiriam e entregar uma autorização para que os pais assinassem. Isto foi necessário tendo em vista que os participantes eram crianças. Todos os pais consultados concordaram que seus filhos participassem do estudo. Estabeleceu-se ainda uma data para a realização da avaliação.

A amostra foi selecionada pelas professoras de cada classe de primeira a quarta série, que escolhiam conforme a classificação Forte/ Fraco. Após essa escolha, as professoras preenchiam a ficha de identificação.

A aplicação coletiva demorou em média trinta a quarenta minutos, incluindo o rapport, para cada grupo de oito crianças. 
A pesquisadora leu em voz alta as instruções, questionou se as mesmas tinham dúvidas, esclareceu-as quando necessário e continuou a aplicação lendo em voz alta cada questão. Foi respeitado o ritmo do grupo. O período de coleta de dados demorou três meses.

Após a realização da pesquisa, foram proferidas palestras para os professores das escolas, com o objetivo de passar a eles conceitos básicos para a compreensão do que é stress e de como poderiam ajudar seus alunos a lidar com ele.

\section{Resultados}

A fim de avaliar os resultados coletados foi feita, inicialmente, uma caracterização dos dados biográficos quanto aos aspectos sexo, idade e a média geral das mesmas. Posteriormente calculou-se a média de idade por série. Procedeu-se o levantamento dos alunos, segundo o conceito Forte e Fraco por série. A seguir foi avaliada a incidência de sintomas de stress na amostra através da avaliação dos resultados do I.S.S.I.. Calculou-se a porcentagem total dos sintomas a nível de freqüência e intensidade apresentados pela amostra total e pelas categorias: alunos fortes meninos e meninas e alunos fracos meninos e meninas.

\section{Caracterização dos dados biográficos}

Dos dados coletados na pesquisa quanto às médias de idade, verificou-se como sendo $\mathrm{a}$ média total de idade da amostra de 158 alunos 9 a e $2 \mathrm{~m}$. A média total de idade das meninas foi de 9 a e $1 \mathrm{~m}$ e a média total dos meninos foi de 9 a e $2 \mathrm{~m}$, conforme mostra a tabela 1 .

Tabela 1. Distribuição das médias de idade dos alunos por série segundo a classificação de alunos fortes e alunos fracos.

\begin{tabular}{|c|c|c|c|c|}
\hline \multirow{2}{*}{ Série } & \multicolumn{4}{|c|}{ Média de Idade } \\
\cline { 2 - 5 } & \multicolumn{2}{|c|}{ Alunos Fortes } & \multicolumn{2}{c|}{ Alunos Fracos } \\
\cline { 2 - 5 } & Meninos & Meninas & Meninos & Meninas \\
\hline $1^{\mathrm{a}}$ & $* 9 \mathrm{a} 1 \mathrm{~m}$ & $7 \mathrm{a} 4 \mathrm{~m}$ & $7 \mathrm{a} 8 \mathrm{~m}$ & 7 a $9 \mathrm{~m}$ \\
\hline $2^{\mathrm{a}}$ & $8 \mathrm{a} 3 \mathrm{~m}$ & $8 \mathrm{a} 1 \mathrm{~m}$ & $9 \mathrm{a} 2 \mathrm{~m}$ & $8 \mathrm{a} 4 \mathrm{~m}$ \\
\hline $3^{\mathrm{a}}$ & $9 \mathrm{a} 5 \mathrm{~m}$ & $9 \mathrm{a} 1 \mathrm{~m}$ & $10 \mathrm{a} 2 \mathrm{~m}$ & $10 \mathrm{a} 6 \mathrm{~m}$ \\
\hline $4^{\mathrm{a}}$ & $10 \mathrm{a} 8 \mathrm{~m}$ & $10 \mathrm{a} 2 \mathrm{~m}$ & $11 \mathrm{a} 7 \mathrm{~m}$ & $12 \mathrm{a} 1 \mathrm{~m}$ \\
\hline
\end{tabular}

\begin{tabular}{|c|c|c|c|}
\hline \multicolumn{2}{|c|}{$\begin{array}{c}\text { Média de Idade dos Alunos } \\
\text { Fortes }\end{array}$} & \multicolumn{2}{c|}{$\begin{array}{c}\text { Média de Idade dos Alunos } \\
\text { Fracos }\end{array}$} \\
\hline Meninos & $9 \mathrm{a} 1 \mathrm{~m}$ & Meninos & 9 a $3 \mathrm{~m}$ \\
\hline Meninas & 8 a $7 \mathrm{~m}$ & Meninas & 9 a $6 \mathrm{~m}$ \\
\hline Média global & 8 a 9 m & Média global & 9 a $9 \mathrm{~m}$ \\
\hline
\end{tabular}

* 2 alunos com 11 anos e 1 aluno com 10 anos

Tabela 2. Distribuição dos participantes da pesquisa quanto ao número de alunos classificados como fortes e fracos por sexo e série

\begin{tabular}{|c|c|c|c|c|c|c|}
\hline \multirow{2}{*}{ Série } & Meninas & Frequência & Porcentagem & Meninos & Frequêencia & Porcentagem \\
\hline \multirow{2}{*}{$1^{\mathrm{a}}$} & Fortes & 15 & $20,83 \%$ & Fortes & 13 & $15,12 \%$ \\
\cline { 2 - 7 } & Fracas & 09 & $12,50 \%$ & Fracos & 20 & $23,25 \%$ \\
\hline \multirow{2}{*}{$2^{\mathrm{a}}$} & Fortes & 06 & $8,33 \%$ & Fortes & 04 & $4,65 \%$ \\
\cline { 2 - 7 } & Fracas & 07 & $9,72 \%$ & Fracos & 06 & 14 \\
\hline \multirow{2}{*}{$3^{\mathrm{a}}$} & Fortes & 10 & $13,90 \%$ & Fortes & $16,97 \%$ \\
\cline { 2 - 7 } & Fracas & 09 & $12,50 \%$ & Fracos & 13 & $15,12 \%$ \\
\hline \multirow{2}{*}{$4^{\mathrm{a}}$} & Fortes & 09 & $12,50 \%$ & Fortes & 06 & $6,97 \%$ \\
\cline { 2 - 7 } & Fracas & 07 & $9,72 \%$ & Fracos & 10 & $11,64 \%$ \\
\hline
\end{tabular}


Procedeu-se também uma análise dos dados quanto ao número de alunos escolhidos por série, dentro da classificação forte e fraco, conforme demonstra a tabela 2 .

\section{Análise dos dados do Inventário de Sintomas de Stress Infantil (I.S.S.I.)}

\section{Amostra global}

Os resultados da avaliação do I.S.S.I., de acordo com as respostas assinaladas pelas 158 crianças que compunham a amostra global, apontam que 88 (ou seja 55\%) apresentam sintomatologia de stress significativa .

Das 158 crianças avaliadas, 70 crianças (ou seja 44\%) não apresentam sintomatologia de stress significativa conforme demonstra a tabela 3 .

Tabela 3. Distribuição da amostra global dos sujeitos quanto à sintomatologia de stress

\begin{tabular}{|l|c|c|}
\hline \multicolumn{1}{|c|}{ Classificação } & Frequência & Porcentagem \\
\hline $\begin{array}{l}\text { Com sintomatologia significativa } \\
\text { de stress }\end{array}$ & 88 & $55,7 \%$ \\
\hline $\begin{array}{l}\text { Sem sintomatologia significativa } \\
\text { de stress }\end{array}$ & 70 & $44,3 \%$ \\
\hline Amostra total & 158 & $100 \%$ \\
\hline
\end{tabular}

Dentre as 88 crianças que apresentaram sintomatologia significativa de stress; 53 (ou seja $60,2 \%$ ) eram alunos fracos sendo 24 meninas (45\%) e 29 meninos (54\%). Os alunos fortes foram 35 (ou seja 39,8\%), sendo 13 meninas (37\%) e 22 meninos $(62 \%)$.

Tabela 4. Freqüência com que os alunos experimentaram os sintomas de stress, meninos e meninas, segundo o critério alunos forte - alunos fracos.

\begin{tabular}{|c|c|c|c|c|}
\hline & \multicolumn{2}{|c|}{ Frequência } & \multirow[b]{2}{*}{ Total } & \multirow[b]{2}{*}{ Porcentagem } \\
\hline & Meninos & Meninas & & \\
\hline Alunos fortes & 22 & 13 & 35 & $39,8 \%$ \\
\hline Alunos fracos & 29 & 24 & 53 & $60,2 \%$ \\
\hline Total & 51 & 37 & 88 & $100 \%$ \\
\hline
\end{tabular}

Quanto aos sintomas de stress, os mais mencionados pela população global foram, no que se refere aos sintomas cognitivos: fico preocupado com coisas ruins que podem acontecer, 111 (70\%); tenho medo, 93 (58\%); tenho vontade de chorar, 91 (57\%) e quanto aos sintomas somáticos: minhas mãos ficam suadas, 102 (64\%); não consigo ficar parado e quieto no mesmo lugar por muito tempo, 90 (56\%); meu coração bate depressa, 89 (56\%). A média de sintomas apontados pela população global foi de 7,9.

\section{Amostra dos alunos classificados como fortes}

Do total de 79 crianças ( meninos e meninas ), 35 (44,3\%) apresentavam sintomatologia significativa de stress e 44 (55,7\%) não apresentavam sintomatologia significativa de stress.

\section{Meninas}

$\mathrm{O}$ número de meninas que compunha a amostra de alunos fortes foi de $40(50,6 \%)$, sendo que $13(33 \%)$ apresentavam sintomatologia significativa de stress e 27 (67\%) não apresentaram sintomatologia significativa de stress.

Avaliando-se a incidência dos tipos de sintoma, verificou-se que os sintomas cognitivos de stress mais mencionados pelas meninas foram: fico preocupada com coisas ruins que podem acontecer, 29 (72\%); tenho medo, 27 (67\%); sou tímida, 23 (57\%) e quanto aos sintomas somáticos de stress os mais mencionados foram: tenho dor de barriga, 26 (65\%); não consigo ficar parada e quieta num no mesmo lugar por muito tempo e meu coração bate depressa, 22 (55\%).

\section{Meninos}

$\mathrm{O}$ número de meninos que compunha a amostra de meninos fortes foi de $39(49 \%)$, sendo que $22(56 \%)$ apresentavam sintomatologia 
significativa de stress e 17 (43\%) não apresentaram sintomatologia significativa de stress.

No que diz respeito aos sintomas cognitivos de stress, os mais mencionados pelos meninos foram: fico preocupado com coisas ruins que podem acontecer e sou tímido, 29 (74\%); tenho vontade de chorar e tenho medo, 26 (66\%). Já os sintomas somáticos mais mencionados foram: não consigo ficar parado e quieto num mesmo lugar por muito tempo, 33 (84\%); minhas mãos ficam suadas, 28 (71\%); meu coração bate depressa e tenho dor de barriga, 26 (66\%).

Os alunos classificados como fortes apontaram para maior incidência de sintomas de stress do tipo cognitivo, com uma média de 4,2. A média de 3,4 para sintomas somáticos. A média total de sintomas cognitivos e somáticos apontados pela população de alunos fortes foi de 7,6.

A Figura 1 demonstra a distribuição dos alunos fortes, meninos e meninas, quanto à presença ou não de sintomatologia significativa de stress.

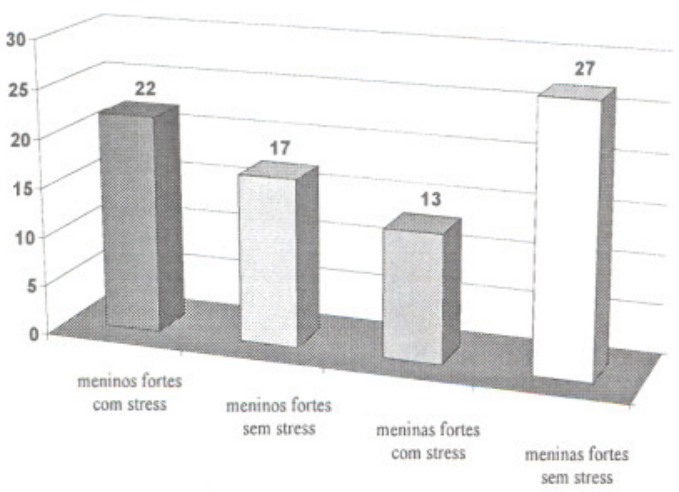

Figura 1. Demonstração dos alunos fortes, ambos os sexos, quanto à sintomatologia significativa de stress.

\section{Amostra dos alunos classificados como fracos}

No que se refere aos alunos fracos, das 79 crianças avaliadas quanto aos níveis de stress,
$53(67 \%)$ apresentaram sintomatologia significativa de stress.

\section{Meninas}

O número de meninas foi de 32 , sendo que $75 \%$ delas apresentavam sintomatologia significativa de stress.

No que diz respeito aos sintomas de stress, os sintomas cognitivos mais mencionados pelas meninas foram: fico preocupada com coisas ruins que podem acontecer e eu me sinto triste, 26 (81\%); tenho vontade de chorar e tenho dificuldades em prestar atenção, 25 (78\%). Os sintomas somáticos de stress mais mencionados foram: minhas mãos ficam suadas, 21 (65\%); tenho dor de barriga e não consigo ficar parado e quieto num mesmo lugar por muito tempo, 20 $(62 \%)$.

\section{Meninos}

$\mathrm{O}$ número de meninos que compunha a amostra de alunos fracos foi de 47 , sendo que $61 \%$ apresentavam sintomatologia significativa de stress.

No que se refere à avaliação dos sintomas cognitivos de stress, os meninos apresentaram como os mais mencionados: fico preocupado com coisas ruins que podem acontecer, 30 (63\%); tenho vontade de chorar, tenho medo e tenho dificuldades em prestar atenção, 29 (61\%); eu me sinto triste, 27 (57\%). Os sintomas somáticos de stress mais mencionados foram: minhas mãos ficam suadas, 37 (78\%); tenho dor de barriga, meu coração bate depressa, não consigo ficar parado e quieto num mesmo lugar por muito tempo, 29 (61\%).

Os alunos classificados como fracos apontaram para maior incidência de sintomas de stress do tipo cognitivo, com média de 4,5. A média foi de 3,6 para sintomas somáticos. A média total de sintomas cognitivos e somáticos 
apontados pela população de alunos fracos foi de 8,1 .

A Figura 2 demonstra a distribuição dos alunos fracos, meninos e meninas, quanto à presença ou não de sintomatologia significativa de Stress.

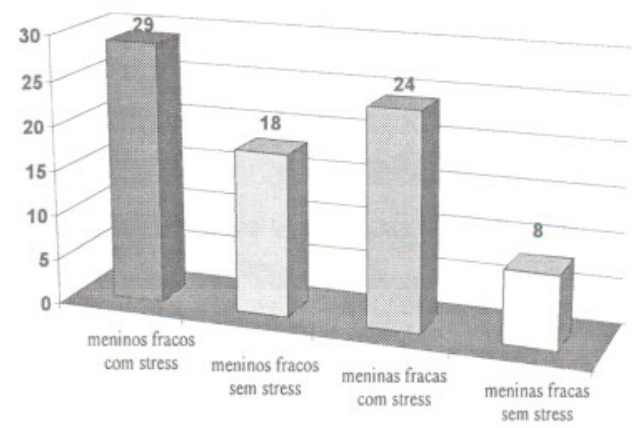

Figura 2. Demonstração dos alunos fracos, ambos os sexos, quanto à sintomatologia significativa de stress.

\section{Distribuição dos alunos quanto à sintoma- tologia de stress no que se refere ao sexo}

No que se refere à sintomatologia do Stress quanto ao sexo, os alunos do sexo masculino apresentam, tanto os classificados como fracos quanto os classificados como fortes, maior indicação de sintomas de stress, conforme demonstra a Figura 3.

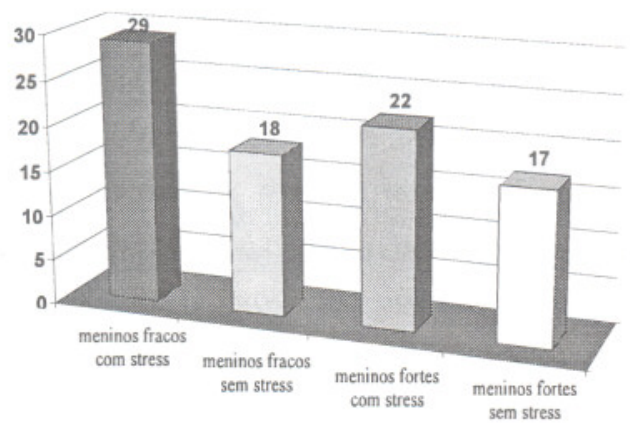

Figura 3. Demonstração dos alunos do sexo masculino quanto à presença ou não de sintomatologia significativa de stress.
Já no que se refere ao sexo feminino, nota-se que as participantes classificadas como alunas fracas apresentaram maior sintomatologia do Stress e as alunas classificadas como fortes apontaram para uma menor indicação da sintomatologia do Stress.

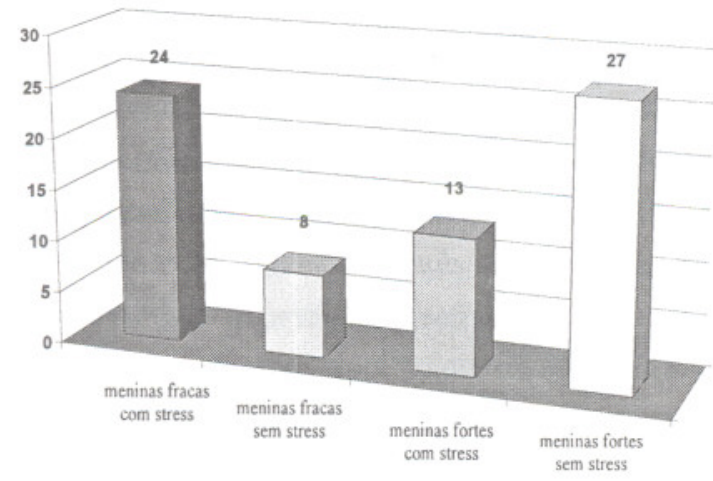

Figura 4. Demonstração dos alunos do sexo feminino quanto à presença ou não de sintomatologia significativa de stress.

\section{Discussão}

O fato de que todos os responsáveis consultados autorizaram a participação dos filhos, representa uma diferença marcante com relação aos estudos realizados por Vilella (1995) e Tricolli (1997), que tiveram recusas. Cabe no entanto ressaltar que, embora nas escolas que aceitaram a pesquisa não tenha havido resistência a participação por parte da direção, dos professores e dos pais e crianças, ocorreu resistência por parte de três escolas que não aderiram a pesquisa. Este dado vem de encontro aos achados em pesquisas realizadas com escolares de primeira a quarta série de alunos de escolas públicas e particulares como o de Bignotto (1996); Vilella (1995) e Tricolli (1997), que relataram dificuldades de adesão e participação em suas pesquisas. Quanto a isso, Bignotto (1996) sugere que quando se trata de cidade pequena, a população pode apresentar desin- 
formação e por isso ocorrer maior resistência. Dessa forma tornam-se mais relevantes os estudos realizados junto às populações de cidades menores, com o intuito de que estas venham a ter acesso ao conhecimento, principalmente de assuntos relacionados à saúde.

O objetivo principal do trabalho foi verificar se os escolares apresentavam significativa sintomatologia de stress, o que foi confirmado, uma vez que $55 \%$ da amostra total aponta para significativa incidência de sintomas de stress.

Sobre a sintomatologia de stress encontrada nesta amostra de alunos de escolas públicas, este estudo está de acordo com os de Vilella (1995) e Tricolli (1997), concluíndo que entre os escolares existia um elevado nível de stress. As autoras mostram em seus trabalhos que tanto crianças da rede pública quanto crianças das escolas particulares, apresentaram significativa sintomatologia de stress, o que as levou a crer que o stress pode ocorrer na infância, independentemente da classe social.

$\mathrm{O}$ interesse em estudar uma amostra formada por alunos de escolas da periferia vem de encontro ao mencionado por Corrêa (1992, apud Tricolli, 1997), que revela serem os índices de reprovação e evasão escolar maiores nas escolas públicas e de periferia.

O fato de avaliar alunos fracos e alunos fortes teve como objetivo verificar se existia uma diferença entre os níveis de stress nessas categorias. Ficou evidente que os alunos fracos, tanto os meninos como as meninas, foram os que apresentaram mais altos níveis de sintomas de stress.

É conveniente ressaltar que não foi propósito da pesquisa buscar relação entre stress e aproveitamento escolar. Em seu estudo, Tricolli (1997) menciona não ter sido possível estabelecer uma relação entre stress e aproveitamento escolar, embora tenha utilizado um instrumento para a avaliação de aproveitamento escolar.
No que diz respeito aos alunos fortes, os meninos foram os que apresentaram maiores níveis de stress com uma predominância de sintomas cognitivos, embora os sintomas somáticos também tenham sido largamente mencionados.

Quanto aos resultados da sintomatologia de stress entre meninos e meninas constatou-se que, na população estudada, os meninos foram os que apresentaram maior incidência de sintomas de stress, tanto aqueles que se encontravam na categoria alunos fortes quanto na categoria alunos fracos.

Os dados em relação à maior sintomatologia de stress entre os meninos, podem servir como ponto de partida para futuros estudos que visem pesquisar as diferenças de níveis de stress no sexo feminino e masculino.

Já Tricolli (1997), no que se refere aos alunos das escolas públicas, constatou que foram os alunos de melhor aproveitamento escolar que apresentaram mais altos níveis de stress.

Quanto às meninas, as classificadas como fracas apresentaram mais sintomatologia de stress.

Quanto ao tipo de sintoma apresentado, um dado importante é que independente do sexo e da classificação de forte e fraco, apareceram mais indicações de sintomas cognitivos.

Estes dados coincidem com os de Vilella (1995), Alcino (1996), Bignotto (1996) e Tricolli (1997).

Os sintomas cognitivos "Fico preocupado com coisas ruins que podem acontecer"; "Eu me sinto triste"; "Tenho vontade de chorar"; "Tenho medo" e "Tenho dificuldades em prestar atenção" foram os mais mencionados tanto pelos alunos fracos quanto pelos alunos fortes de ambos os sexos.

Quanto aos sintomas somáticos, chama a atenção a alta incidência de citações dos sintomas "Tenho dor de barriga", "Não consigo ficar parado e quieto num mesmo lugar por muito tempo "e "Meu coração bate depressa". 
A presença de dor abdominal quando não associada a causas físicas, segundo Sharrer e Wenger (apud Vilella, 1995) está relacionada ao stress excessivo. "Meu coração bate depressa" é um sintoma relacionado à ansiedade, que também foi observado na população estudada por Vilella (1995). Esses sintomas também foram mencionados com alta freqüência pelos participantes dos estudos de Vilella (1995) e Tricolli (1997).

Tendo em vista os significativos níveis de stress apresentados pelas crianças da rede pública que compõem esta amostra, seria interessante e pertinente que trabalhos com o intuito de avaliar quais as fontes externas e internas de stress que estão mais presentes na vida das mesmas, fossem realizados no futuro.

Tricolli (1997) coloca ter encontrado relação entre stress e fontes internas e externas de stress tanto no relato das mães quanto das próprias crianças da população por ela estudada. Também Vilella (1995) encontrou um significativo número de fontes de stress junto à população de escolares por ela estudada. Sem dúvida, a criança em idade escolar convive com um grande número de situações que colaboram sobremaneira para que ela se estresse.

Alguns dados indicam para esse caminho.

Entre eles o postulado por Lipp et al (1991) segundo a qual a escola pode ser um fator estressante para as crianças que a freqüentam, tendo em vista que em muitos casos estas não respeitam suas expectativas, as condições físicas podem ser inadequadas, o material pedagógico inapropriado, a desinformação e o stress do professor, além do medo e anseios próprios dos estágios de desenvolvimento da criança; assim como o estudo de Vilella (1995), segundo o qual as próprias mães citam a família como uma fonte geradora de stress em função da vida estressante que a sociedade vive, com as atribuições dos pais e mais particularmente da mãe, com dupla jornada de trabalho.
Também é um fator relevante ter-se constatado entre as professoras participantes total desinformação sobre os conceitos e sintomas de stress, o que está de acordo com os achados de Tricolli (1997).

A problemática existe, é portanto cada vez mais necessário que se chame a atenção de futuros estudiosos para esta parcela da população, assim como dos adultos que participam diretamente na sua formação.

Dessa maneira, um trabalho de prevenção poderá ser realizado, com o intuito de se tornar as futuras gerações mais capazes para lidar com as tensões do dia a dia.

\section{Conclusão}

O presente estudo teve por objetivo avaliar a sintomatologia de stress em crianças da rede pública de ensino da periferia da cidade de Americana.

Esta população foi escolhida por pensarse que dadas as suas condições sócio econômicas, esta seja uma parcela da população que mais anseie para que os estudiosos tomem conhecimento de sua problemática.

Pode-se constatar que esta população apresenta uma significativa incidência de sintomas de stress, principalmente entre os alunos classificados como fracos.

O fato desta amostra apontar para uma maior incidência de sintomas cognitivos caracteriza-a na Fase de Alerta do stress, porém temos que considerar os sintomas de stress somáticos, que também foram freqüentemente mencionados.

Os resultados revelaram que a criança assim como o adulto pode ser portadora de sintomatologia de stress e que portanto, novos pesquisadores tem na área do Stress Infantil um assunto de importância relevante no campo da Psicologia Clínica e Educacional, tanto a nível de controle como de prevenção. 


\section{Referências bibliográficas}

Alcino, A. B. ( 1996 ). Stress Social e Reatividade Cardiovascular Infantil: Um Estudo Psicofisiológico. Dissertação de Mestrado. Departamento de Pós - Graduação em Psicologia Clínica. PUC-Campinas.

Bandura, A. ( 1963 ). Agression: a social learning analysis. New Jersey: Prentice-Hall.

Biaggio, A. M. B. ( 1988 ). Psicologia do Desenvolvimento. Petrópolis.

Biaggio, A. M. B.; Machado, S. ( 1990 ). Adaptação para o Português do STAXI, de Spielberg Estudos preliminares com sujeitos bilíngües. Porto Alegre: SBPC.

Bignotto, M. M. ( 1997 ). Stress e suas fontes na Ontogênese e Manutenção da Obesidade Infantil. Dissertação de Mestrado. Departamento de Pós-Graduação em Psicologia Clínica. PUC-Campinas.

Carson, K.; Schauer, R. W. ( 1992 ). Children's Temperament and Coping Abilities. Journal Genet-Psychal, vol. 3.

Corrêa, M.R.A. ( 1992 ). Fatores Familiares e Aproveitamento Escolar em uma Escola Pública da Periferia de São Paulo. Dissertação de Mestrado. Faculdade de Ciências Médicas. UNICAMP.

Cummings, E. M. ( 1987 ) Coping with background anger in early childhood. Child Development, vol. 58 , pp. $976-984$.

Kowal, A.; Pritchard, Dom ( 1990 ). Psychological Characteristics of Children Who Suffer from Headache: a research. Journal Child Psychiat, vol. 31, p.p. . Adelaide.

Lamude, K.G. ( 1992 ) Resistence in the College Classroom: Variations in Student's Perceived Strategies for Resistence and Teacher's Stressors as a Function of Student's Ethnicity. Perceptual and Motor Skills, vol. 75, p.p. 616-626.

Lima, G.Z. et al ( 1985 ). A criança na Escola, in MARCONDES, D. E., Pediatria Básica. São Paulo: Sarvier, p.p. $69-74$.

Lima, E.C. ( 1992 ). Obesidade: a contribuição do estresse e de alguns fatores psicológicos no seu desenvolvimento e Manutenção. Dissertação de Mestrado. Departamento de Pós - Graduação em Psicologia Clínica. PUC - Campinas.

Lipp, M. N. ( 1989 ). Atitudes Parentais do Desenvolvimento de Resistência ao Estresse, Psicologia: reflexão e crítica, vol. 4, p.p.

Lipp, M. N. ; Romano. A. S. ; Covolan, M. A. ; Nery, M. J. G.( 1991 ). Como enfrentar o Estresse. São Paulo: Ed. Ícone.

Lipp, M. N.; Souza, P. A. E.; Romano. F. S. A.; Covolan, M. A.; ( 1991 ). Como enfrentar o Stress Infantil. São Paulo: Ed. Ícone.

Reinhold, H. H. ( 1985 ). Fontes e Sintomas do Stress Ocupacional do Professor I. Dissertação de Mestrado. Departamento de Pós-Graduação em Psicologia Clínica. PUC - Campinas.

Tricolli, A.V. ( 1997 ). Sintomas de stress em escolares de $1^{a}$ a $4^{a}$ série. Dissertação de Mestrado. Departamento de Pós - Graduação em Psicologia Clínica. PUC - Campinas.

Vilella, M. ( 1995 ), Sintomas e Fontes de Stress em uma Amostra de Escolares da Primeira a Quarta Série. Dissertação de Mestrado. Departamento de Pós - Graduação em Psicologia Clínica. PUC - Campinas. 